UCRL-ID-129741

\title{
Feasibility of Using an East Coast Facility for Collaborative Research in Atmospheric Science
}

\author{
John D. Molitoris \\ Demetrius D. Venable
}

February 9, 1998

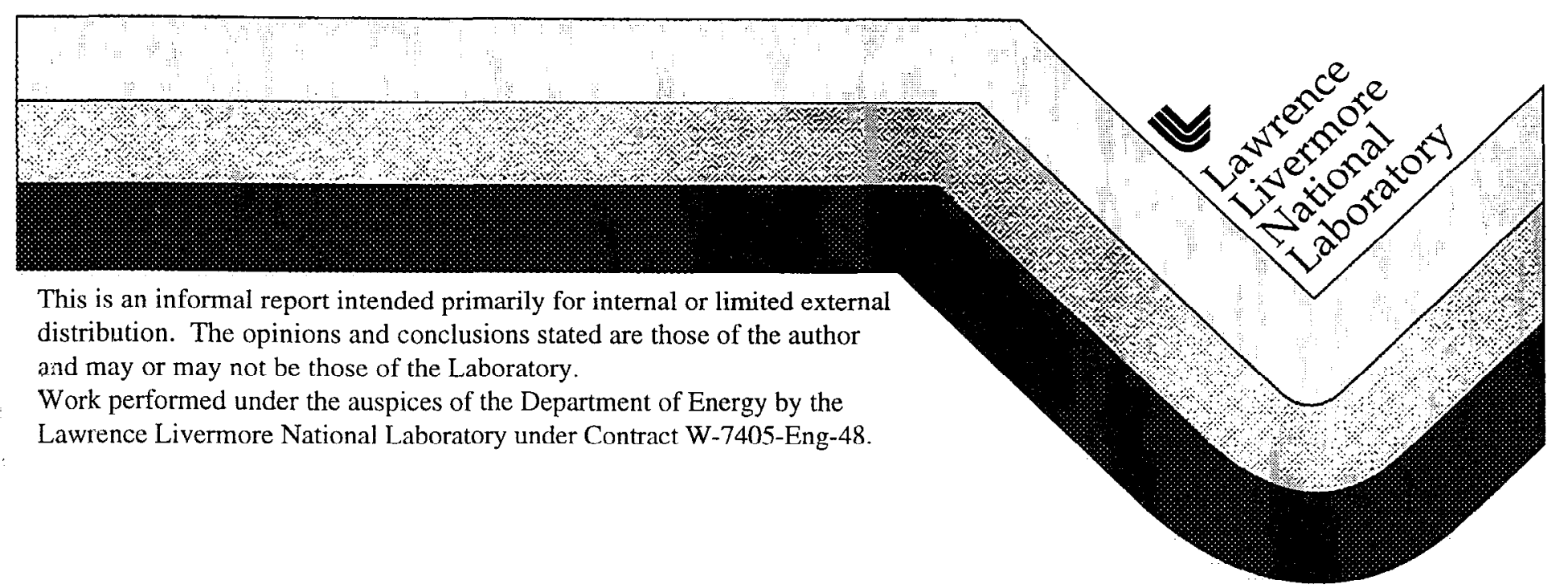




\section{DISCLAIMER}

This document was prepared as an account of work sponsored by an agency of the United States Government. Neither the United States Government nor the University of California nor any of their employees, makes any warranty, express or implied, or assumes any legal liability or responsibility for the accuracy, completeness, or usefulness of any information, apparatus, product, or process disclosed, or represents that its use would not infringe privately owned rights. Reference herein to any specific commercial product, process, or service by trade name, trademark, manufacturer, or otherwise, does not necessarily constitute or imply its endorsement, recommendation, or favoring by the United States Government or the University of California. The views and opinions of authors expressed herein do not necessarily state or reflect those of the United States Government or the University of California, and shall not be used for advertising or product endorsement purposes.

This report has been reproduced directly from the best available copy.

Available to DOE and DOE contractors from the Office of Scientific and Technical Information

P.O. Box 62, Oak Ridge, TN 37831

Prices available from (615) 576-8401, FTS 626-8401

Available to the public from the

National Technical Information Service

U.S. Department of Commerce

5285 Port Royal Rd.,

Springfield, VA 22161 


\title{
FEASIBILITY OF USING AN EAST COAST FACILITY FOR COLLABORATIVE RESEARCH IN ATMOSPHERIC SCIENCE
}

\author{
John D. Molitoris \\ Earth and Environmental Sciences \\ Lawrence Livermore National Laboratory \\ Livermore, California \\ Demetrius D. Venable \\ Department of Physics and Astronomy \\ Howard University \\ Washington, D. C.
}

\begin{abstract}
This feasibility study examined the effectiveness and potential of a center for collaborative research in atmospheric science and remote sensing. Strongly related to this effort was the development of a telescope facility by Howard University into an atmospheric observatory and remote sensor test-bed. Several remote sensing techniques were evaluated here and the most promising were further developed. Atmospheric assessment concentrated on aerosols, winds, constituent analysis, and the detection of hazardous agents including biologicals. This mission defined the suite of instrumentation. Being a feasibility study, the scope of the project was limited to examining the state of the technology and pushing it when possible. Research performed in applying laser technology lead to the development and subsequent patent application of a new laser heterodyne amplifier, progress toward the development of a laser probe to determine the range resolved size distribution of aerosols, and studies which may lead to the development of a laser induced fluorescence sensing technique for biologicals in the atmosphere. Research in passive atmospheric sensing helped to motivate a field experiment to better understand atmospheric radiance and radiation transport in three-dimensions.
\end{abstract}

\section{Motivation}

Research performed here is related to the experimental effort in Remote Sensing and Environmental Measurements within the Health and Ecological Assessment Division at Lawrence Livermore National Laboratory. Primary motivation for this work is to explore the utility of detailed real-time atmospheric measurements in the vicinity of major metropolitan areas to determine their value for environmental studies regarding pollutants and the detection / tracking / dispersion of hazardous agents released into the atmosphere including biological agents. The method included examining current laser technology and applying it to key issues in remote sensing, forming a better understanding of atmospheric radiation transport for passive constituent analysis, and exploring the detection and unique identification of biological contaminants entrained in the atmosphere

\section{Observational facility and Remote Sensing Test-bed}

All of the sensor development cited here relates to a common goal in assessing the state of the atmosphere. The wind measurements are necessary to determine atmospheric transport, aerosol concentration and size affect atmospheric chemistry, laser induced fluorescence can possibly be used for remote sensing of biologicals, and the anomalous absorption in the measured radiance allows the identification and concentration determination of a broad range of foreign agents in the atmosphere. The progress made in active and passive remote sensor development is focused on performing atmospheric 
measurements for environmental science and national security [1]. The test site for these measurements is a telescope facility in Beltsville, MD which is evolving into the Howard University Atmospheric Observatory (HUAO)[2]. Development of the HUAO is an ongoing effort supported by Howard University through the Dept. of Physics and Astronomy. This project merged remote sensing technology at and laboratory facilities at LLNL with the field measurement capabilities of the HUAO. The location of the HUAO (shown in the map below, figure 1) is ideally situated between Washington, D. C. and Baltimore, MD for measurements relating strongly to both metropolitan regions.

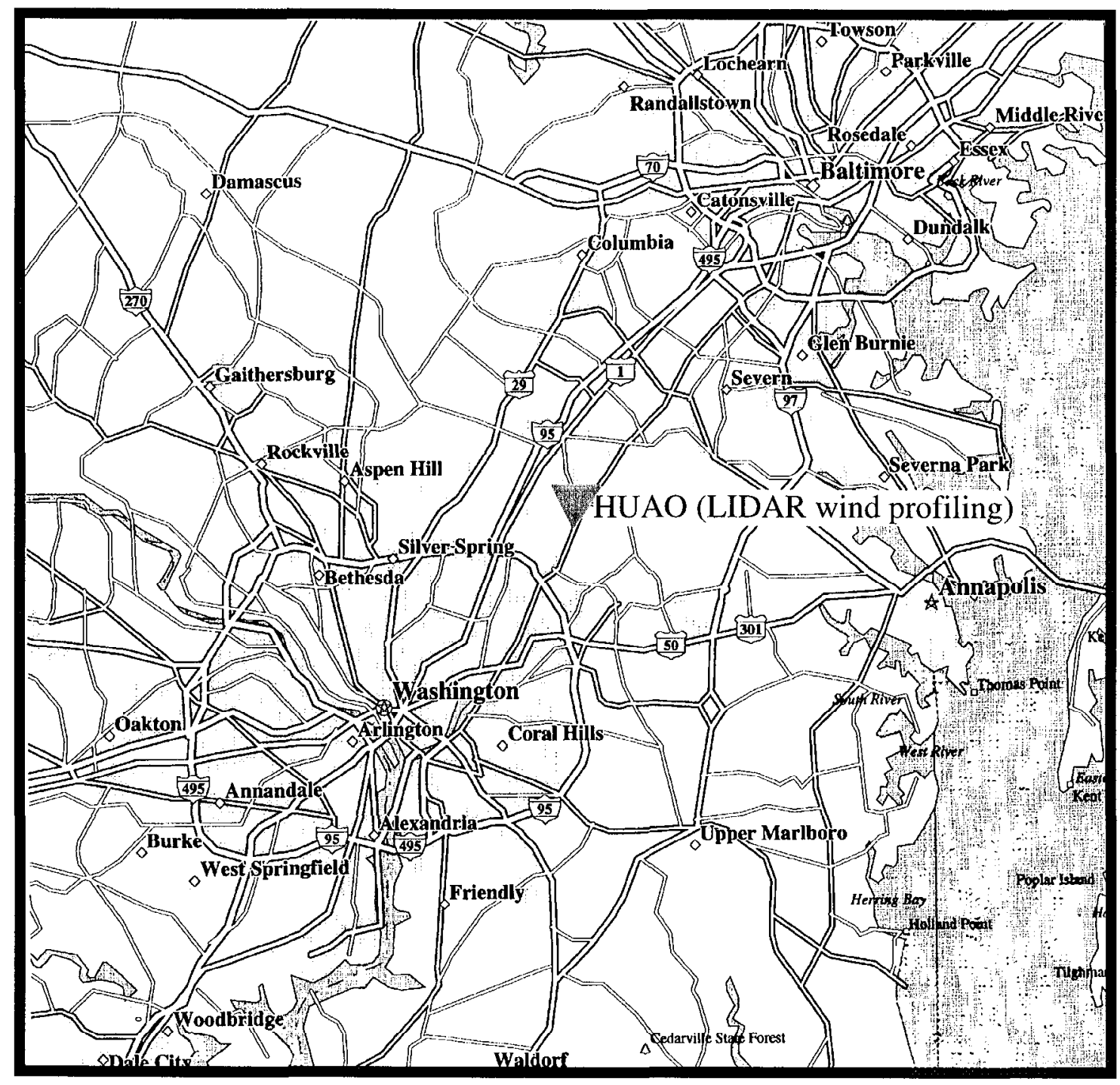

Figure 1. Location of the HUAO in the Washington / Baltimore area.

The rolling topography of the region makes the site ideal for the collection of wind and pollution data important to both cities. Furthermore, range resolved wind data from the HUAO could be an essential element for high accuracy estimates of the dispersion and flow of possible atmospheric releases of hazardous materials including chemical, biological, and radiological agents. Due to the national significance of this area, our atmospheric research and field data will impact the mitigation of the possible threat of terrorist activity and can be used to improve simulations for higher security. 
In addition to remote sensor progress, much progress was also made on the HUAO in order to prepare for field observations. This collaboration helped upgrade the optics of the 30 " telescope and devise a computer control system for the facility which will be implemented in 1998. In progress are also a beam transport system from the support building into the telescope dome and a data acquisition system for the multiple sensor observations. Associated funds from Howard University were also used to upgrade the physical plant of the HUAO and make general improvements. The telescope dome and primary support building of the HUAO is shown below (figure 2).

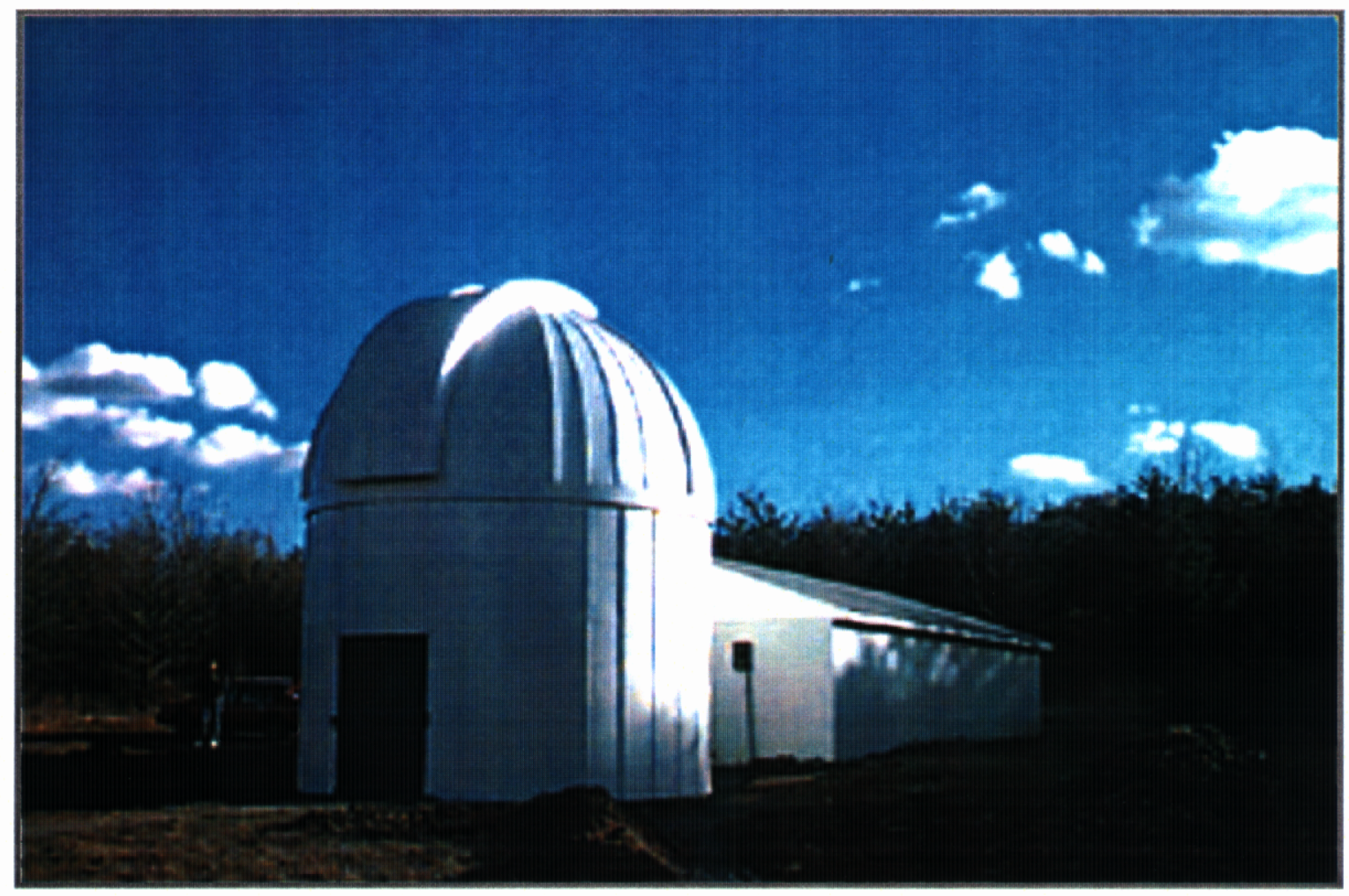

Figure 2. The HUAO is the field station being used for this project. Shown is the telescope dome and support building located at the Howard University Research Park in Beltsville, MD.

\section{Applications of Lasers to Remote Sensing}

The laser is an ideal tool to perform columnar range resolved measurements of the atmosphere [3]. Such laser remote sensing is called lidar, for light detection and ranging. In general there are two types of lidars centering on direct- or indirect-detection of the return signal and both techniques were implemented in this project.

\section{Indirect Detection LIDAR}

The indirection detection lidar being developed improves upon a heterodyne technique which mixes a sample of the outgoing beam with the return signal [4,5]. The resulting frequency analyzed spectrum clearly illustrates any shift between the two signals. As this lidar utilizes very narrow line-width lasers $(<5 \mathrm{KHz}$ over $1 \mathrm{~ms})$ which have large coherence lengths, it can be used to measure motion up to distances of $30 \mathrm{~km}$ away. As 
our goal is to use this lidar to understand turbulence in the boundary layer by measuring the motion of entrained particles and aerosols with high spatial and temporal resolution [6], we concentrated on increasing the sensitivity of the heterodyne receiver. Higher sensitivity detection also enables the use of lower power lasers. Research for this project helped lead to the development of a cavity re-injection technique [7] which can increase the sensitivity up to a factor of 1000 over normal laser Doppler volocimetry and decrease sampling time to $<1 \mathrm{~ms}$.

This technique requires further refinement and development, but we have tested it for wind sensing. Figure 3 shows a comparison of the wind velocity between the lidar and a calibrated air velocity transducer. The agreement is very good, but there is more work to be done to translate this instrument into a field unit for boundary layer turbulence studies. Advances in this type of lidar can be applied to any type of remote sensing requiring high sensitivity motion detection. In fact, as the return signal strength increases as the size of the object being detected is increased, aerosol / particle detection is the most stringent test of this lidar.

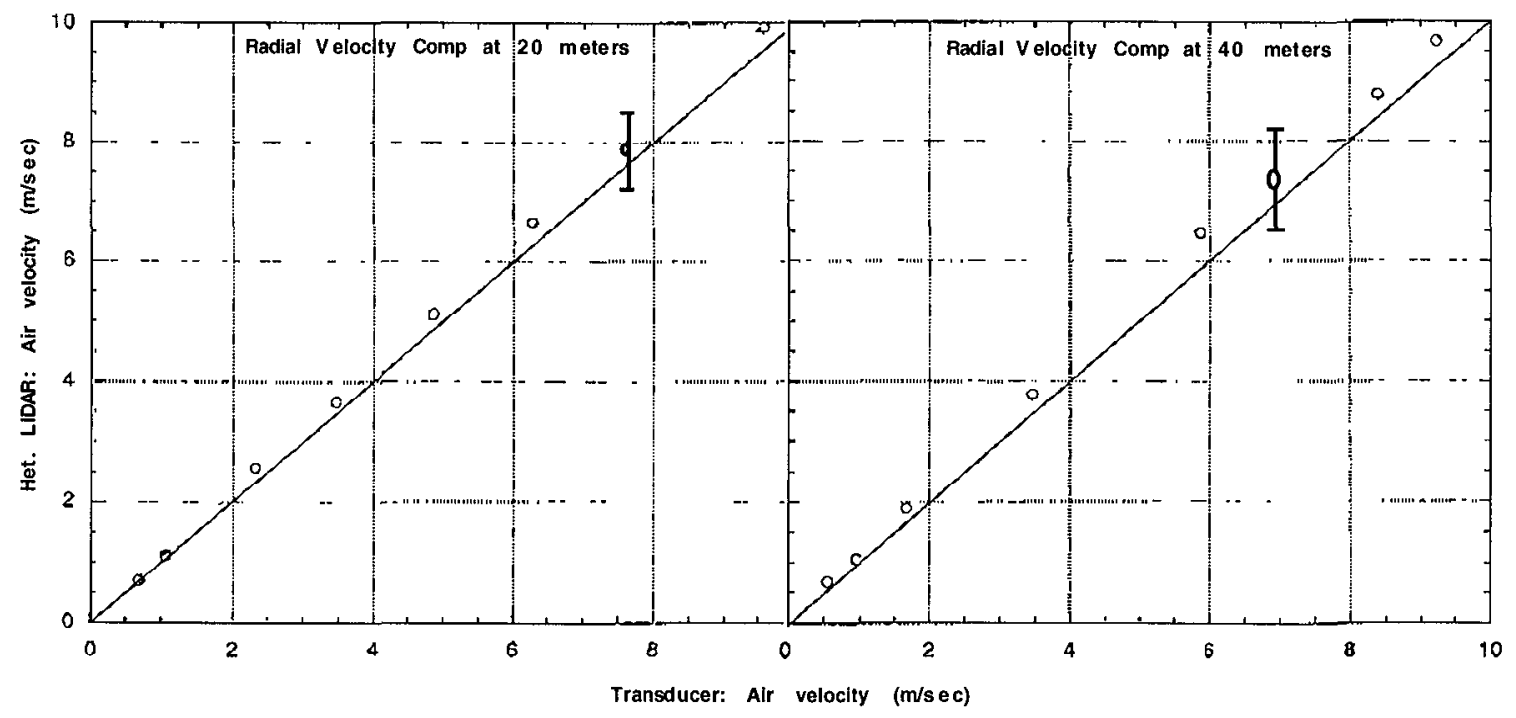

Figure 3. The radial velocity is the component parallel to the laser probe beam. The data shows a comparison between the lidar and a calibrated transducer of a controlled ambient air jet at two distances. Each data point required only a 15 micro second sampling time. Largest error is shown.

\section{Direct Detection LIDAR}

We also examined direct detection backscatter lidar [3] for atmospheric constituent analysis. Unlike the instrument described above, this lidar directly detects backscattered photons. Single wavelength backscatter lidars can be used to detect and quantify structure in the atmosphere such as pollution layers or sub-visible clouds (figure 4). Our work with this lidar is leading to the development of a multiple wavelength backscatter system to not only determine concentration, but particle size distribution. The multi-wavelength approach will allow us to extract the moments of the size distribution as a function of range. The key questions are how many wavelengths are necessary and how well can we calibrate the instrument. Calibration can be performed in the remote sensing laboratory at LLNL using a 3 meter test cell to set up a known aerosol/particle distribution. The calibration translates to improved accuracy in field measurements which are performed at the Howard University 
Atmospheric Observatory (HUAO). The pilot data shown below is taken with a single wavelength backscatter lidar. These data show fine scale structure as well as multiple layers in descending cirrus clouds. The range resolution here is $24 \mathrm{~m}$ with a temporal resolution of 30 seconds.

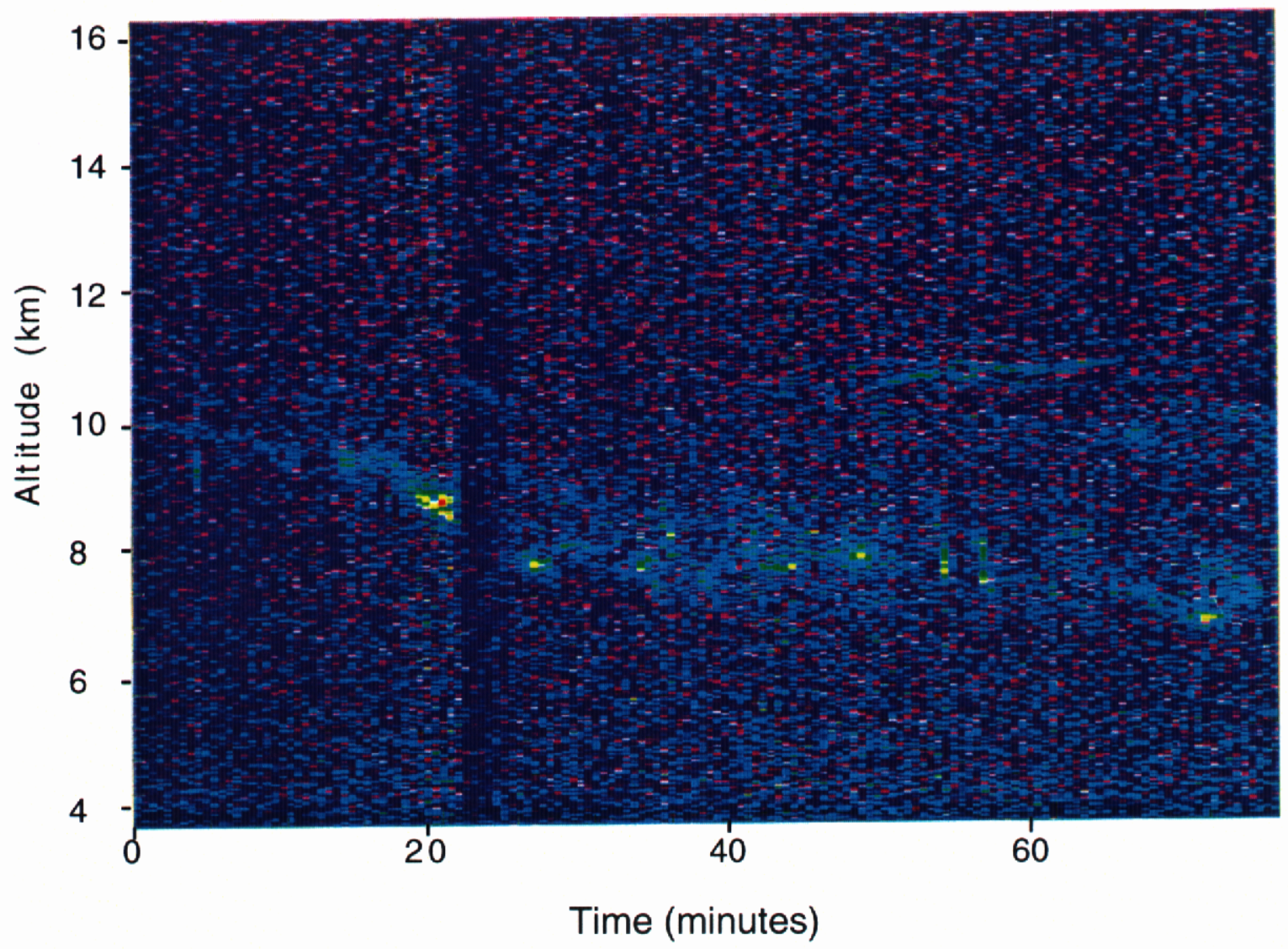

Figure 4. Single wavelength backscatter lidar data as a function of time illustrates the instruments ability to see through cirrus clouds and to altitudes of $16 \mathrm{~km}$. Our research is improving upon this type of lidar to also determine the size distribution of the scatterers.

\section{Laser Induced Fluorescence}

The detection and identification of biological organisms entrained in the atmosphere is a difficult problem due to several factors. Usually, the most significant of these factors is that spectral signatures from a broad variety of organisms are not sufficient to identify them uniquely. In order to obtain a unique signature we explored using a multi-wavelength laser to induce fluorescence. The emission spectrum is then a function of the excitation wavelength which can allow for a more unique signature and better identification. Laboratory studies examining a range of innocuous biological organisms show distinct emission spectra as a function of excitation wavelength. Two examples of these emission excitation "surfaces" are shown below in figures $5 \mathrm{a} \& \mathrm{~b}$. These examples illustrate both the similarities and differences for two related organisms. The main similarity is in the longer emission wavelengths which show a double-humped feature for both materials. The two biologicals differ drastically at the lower wavelength part of the emission spectral. The factor of two difference in the emission intensity between the data is probably due to the composition of the biological. 
Laser induced fluorescence spectroscopy has already been successfully used for in situ detection of biologicals [8] and shows promise as an atmospheric remote sensing technique for biologicals and certain atmospheric constituents (ozone) [9].
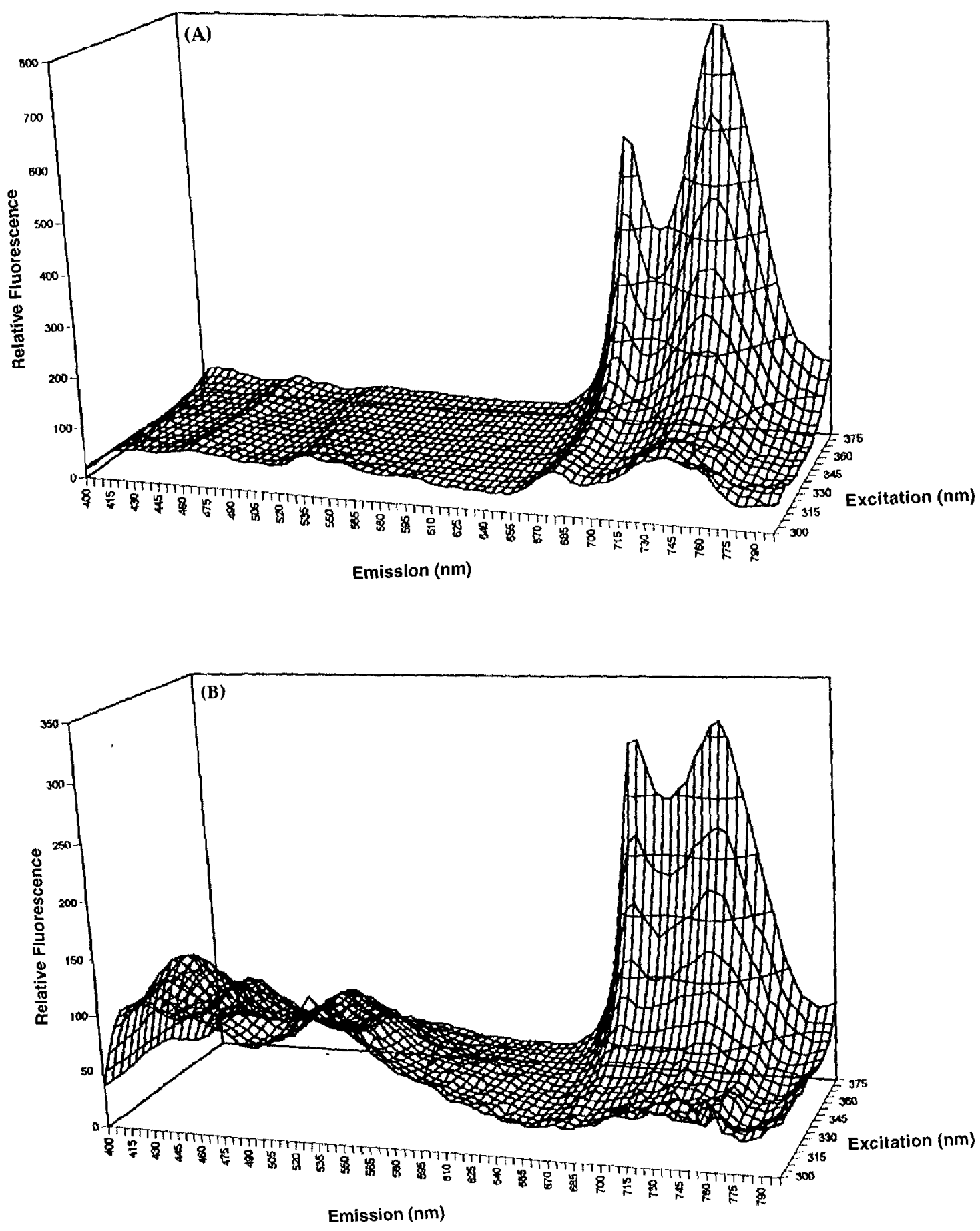

Figure 5. Emission spectra for two biologicals as a function of excitation wavelength. 


\section{Atmospheric Radiance and Radiation Transport in 3-D}

Although the computing power is available, atmospheric radiation transport modeling in three-dimensions is far from being well developed. In fact, the development of 3-D transport models requires a high degree of validation and comparison with field data. Such field data must be spectrally resolved and be able to take narrow columnar measurements while the sky dome is being monitored for changes in the cloud field. In order to better understand atmospheric radiation transport in a real three-dimensional world we are outfitting and testing three instruments for a field experiment to be run at the HUAO. These include a UV/optical spectrometer with a spectral range from 0.2 to 1.2 microns, an infrared imaging spectrometer with a spectral range of 2.0 to 28 microns, and a whole sky imaging (WSI) system. The optical spectrometer has been tested in the laboratory and is nearly ready for field measurements. The observational set-up is illustrated in figure 6 below which shows the whole sky dome.

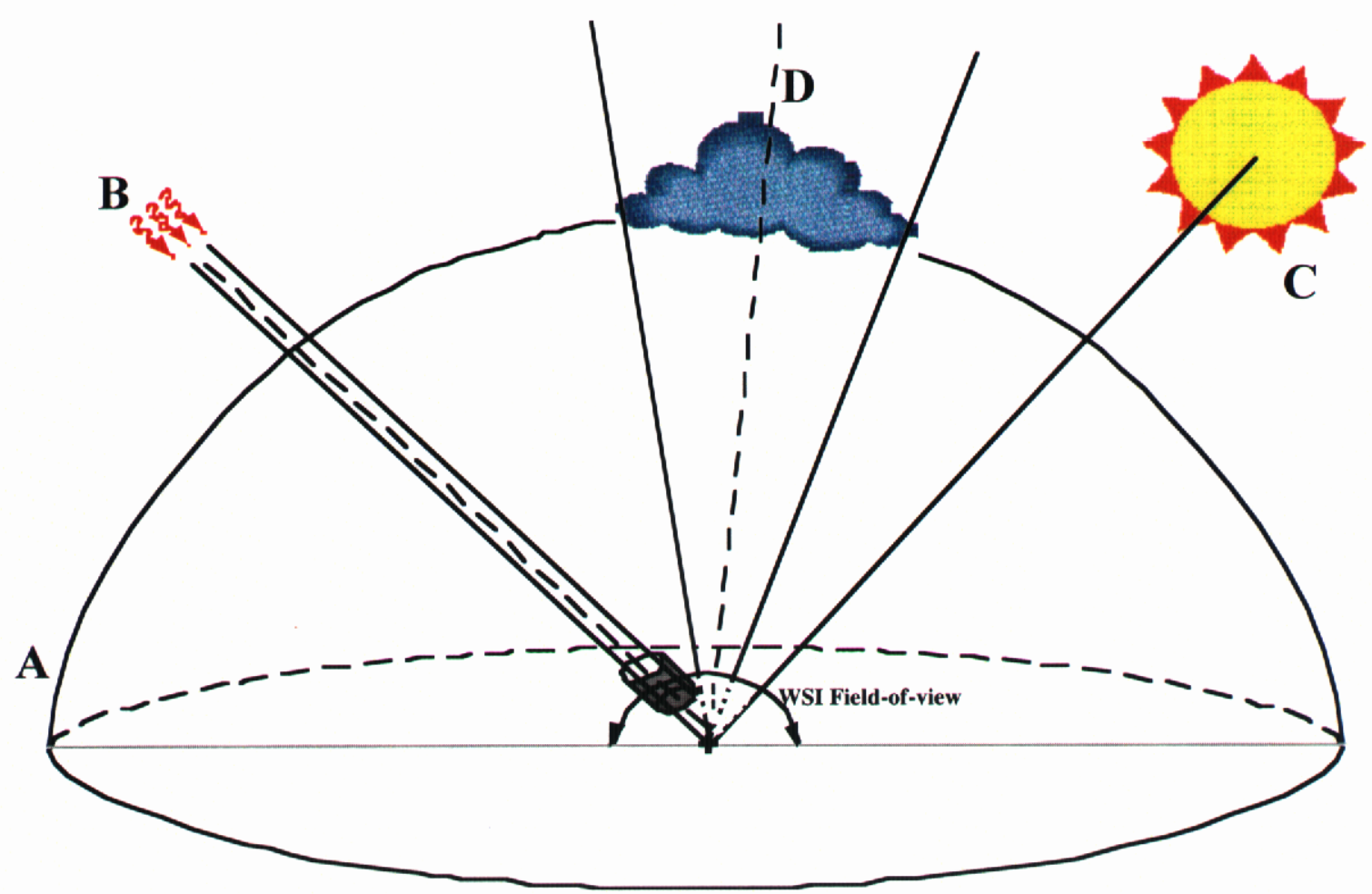

Figure 6. Schematic of full sky dome imaged by the WSI to determine locations of clouds and the sun. The spectrally resolved data is taken in a narrow column with either a dual Cassegrain UV/Optical spectrometer or an IR imaging spectrometer.

Here the WSI determines the angular relationship of objects within the dome to the columnar $(<0.05$ degree) spectral measurement. The spectral irradiance of direct sunlight after it passes through the earth's atmosphere is clearly affected by absorption and falls within the envelope of the calculated black body irradiance. This is always valid for a true clear sky measurement, but three dimensional effects from clouds (scattering) can manifest as excursions beyond the expected black body limit. The experiment will quantify these features and relate them to cloud and cloud field properties. This experiment/field study is part of a student Ph.D. thesis (A. Farah) on atmospheric radiance. Under this project we re-outfitted and began testing two of the three required instruments. Once the optical 
spectrometer and WSI are fielded at the HUAO, the spectrally resolved infrared imager will be readied.

\section{Conclusions}

This project combined the expertise of several institutions to examine the feasibility and advantages of a collaborative research effort in atmospheric science and remote sensing centered around a common set of goals and based at a common facility. We were able to identify and make progress on three different types of laser remote sensing with research in one of these areas being significant enough to result in a patent application. We also began an experiment to study atmospheric radiance and relate the observations to attempts to model atmospheric radiation transport in three dimensions. In addition to the progress in instrument development, this feasibility study brought together a team of scientists from LLNL, Howard University, U. C. Berkeley, Pennsylvania State University, and Kennedy Space Center to define a scientific mission for the Howard University Atmospheric Observatory and solve technical problems associated with embarking on that mission. The scientific mission and research performed here is providing a sound basis for securing long term funding for the facility which will continue to be of value to the mission of Environmental Sciences at LLNL.

\section{Acknowledgements}

The authors would like to sincerely thank Rokaya Al-Ayat and John Holzrichter for their support of this project and the collaboration between LI.NL. Environmental Sciences and Howard University. We acknowledge valuable input and discussions with Dr. Andrew Schuerger (Kennedy Space Center), Prof. Timothy Kane (Pennsylvania State University), and Dr. J. F. Arens (Space Sciences Laboratory, University of California, Berkeley).

This work was supported in part by the Laboratory Directed Research and Development Program, Lawrence Livermore National Laboratory. Work was performed under the auspices of the U. S. Dept. of Energy by the Lawrence Livermore National Laboratory under contract No. W-7405-Eng-48.

\section{References}

1) J. D. Molitoris, E. I. Davis, S.G. Peglow, D. D. Venable, P. E. Smith, "Development of Emplaced Sensors for Atmospheric Assessment," SPIE AeroSense '97 Symposium, Conference on Peace and Wartime Applications and Technical Issues for Unattended Ground Sensors, Orlando, FL (UCRL-JC-127310 Abs).

2) D. D. Venable, A. Farah, J. D. Molitoris, E. I. Davis, "Development of an Atmospheric Observatory for Research in Remote Sensing," Spring 1997 Meeting of the AGU, Baltimore, MD (Submitted by Howard Univ.)

3) R. M. Measures, "Laser Remote Sensing, Fundamentals and Applications", Krieger Publishing Co., Malabar, Florida, 1992.

4) S. G. Peglow and J. D. Molitoris, "Pre/Post-Strike Atmospheric Assessment System", UCRL-ID-126733, February 3, 1997.

5) J. D. Molitoris, E. I. Davis, J. F. Arens, D. D. Venable, "Development of a Portable Wind Sensing LIDAR," Fall 1996 Meeting of the AGU, San Francisco, CA (UCRL-JC$125075 \mathrm{Abs})$. 
6) J. D. Molitoris, E. I. Davis, D.D. Venable, A. Farah, "Development of a LIDAR for Aerosol and Turbulence Measurements in the Boundary Layer," Spring 1997 Meeting of the AGU, Baltimore, MD (UCRL-JC-126755 Abs).

7) J. D. Molitoris, "Cross-Cavity Re-Injection for Laser Heterodyne Amplification"; DOE Invention Case No.: S-88,556 (RL-13974);LLNL Invent. Docket No.: IL-10163; Inventor: John D. Molitoris.Date Disclosed: April 25, 1997, Patent Applied for: August 13, 1997.

8) R. G. Pinnick, S. C. Hill, P. Nachman, G. Videen, "Aerosol Fluorescence Spectrum Analyzer for Rapid Measurement of Single Micrometer-Sized Airborne Biological Particles," Aerosol Science and Technology, 28:2 February 1998.

9) J. L. Guagliardo, "A Feasibility Study of Ozone Remote Sensing by Laser Induced Fluorescense, " $\mathrm{Ph} . \mathrm{D}$. Dissertation, The Louisiana State University and Agricultural and Mechanical College, 1973. 


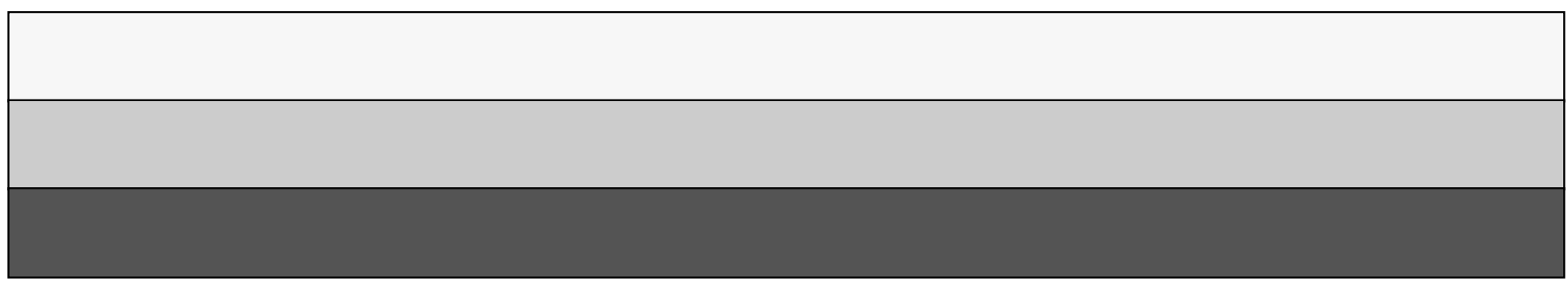

